\section{Students Teaching Students: Undergraduate Students as Laboratory Instructors}

\author{
Elsa Sánchez ${ }^{1,3}$ and Richard Craig ${ }^{2}$
}

\begin{abstract}
ADDITIONAL INDEX WORDs. student instructors, teaching methods, plant systematics
SUMMARY. Undergraduate students teach laboratory sessions in the plant systematics course at The Pennsylvania State University. To assess student-taught laboratory sessions, surveys were administered to student instructors and students enrolled in the course. Benefits to student instructors included increased technical knowledge, new perspectives on teaching methodologies, and acquiring a positive item to add to résumés. Student instructors also practiced leadership skills. Enrolled students generally assessed the laboratory sessions favorably. Organization and planning were vital to the success of this teaching method. This teaching method also required increased departmental funding relative to other courses.
\end{abstract}

$\mathrm{P}$ lant systematics is a sophomore level, 3 -credit, required course for undergraduate students majoring in horticulture offered through the Department of Horticulture at The Pennsylvania State University. The course consists of twice weekly lecture sessions (each $50 \mathrm{~min}$ long) and one weekly laboratory session (115 min long). Laboratory sessions emphasize 14 major plant families, representing the subclasses developed by Cronquist (Walters and Keil, 1996). Families include the Nymphaeaceae, Rosaceae, Asteraceae, Cucurbitaceae, Cactaceae, Fagaceae, Liliaceae, and Poaceae.

Individual laboratory sessions are developed and taught by undergraduate students who have completed the plant systematics course in a previous year. Each year, all students enrolled in the course are extended the opportunity to teach in subsequent years. Appropriate motivational incentives can increase the success of course activities by encouraging participation (Henneberry and Beshear, 1995; Murano and Knight, 1999b). As an incentive to teach,

Use of trade names does not imply endorsement of the products named or criticism of similar ones not named.

The authors express sincere appreciation to Kenneth Myers for his support of this class in the roles of greenhouse technician and teaching assistant and to the numerous graduate and undergraduate teaching assistants for their efforts.

${ }^{1}$ Assistant Professor, Department of Horticulture, The Pennsylvania State University, University Park, PA 16802

${ }^{2}$ J. Franklin Styer Professor Emeritus of Horticultural Botany, The Pennsylvania State University, University Park, PA 16802.

${ }^{3}$ Corresponding author. E-mail: esanchez@psu.edu students can earn one 200-level credit in independent studies, which advances the completion of their baccalaureate degree in horticulture.

In addition to earning academic credit, students increase their technical knowledge of plant systematics by becoming more proficient on a particular plant family. To effectively communicate, student instructors must have a thorough understanding of the concepts they are teaching, which is an important outcome of problem-based learning (Duch, 1996). Through their teaching experience, students also develop leadership skills, including in written and oral communication, which can be beneficial in their future agricultural careers (U.S. Department of Labor, 2006). Leadership skills are sought after in many careers in agriculture, including those in extension (Fehlis, 2005; Moore and Rudd, 2005) and rural cooperatives (Wadsworth, 2003).

Each laboratory session consists of an oral presentation, in-class handout, applied exercises, and a homework assignment. These materials are designed to include visual, auditory and kinesthetic learning activities to aid in teaching effectiveness (Murano and Knight, 1999a) by addressing differences in student learning styles (Murphrey and Boyd, 2003). Student instructors work independently on developing teaching materials; however, the course instructor reviews materials to ensure that the content is thorough, accurate, and appropriate. Granting the students discretion in developing materials encourages creativity and builds independent learning skills (Cox, 1993). Student instructors approach developing teaching materials from the perspective of recently having completed the course. This perspective provides them with insight to the needs of the currently enrolled students. They can develop materials based on those needs as well as their assessment of materials used when they were enrolled in the course. Student instructors' grades are based on completion of required teaching elements as well as attending two $1-h$ planning meetings, each once per week in the 2 weeks before the laboratory session.

At the beginning of each laboratory session, the student instructor is formally introduced to the class by the course instructor or a teaching assistant (Fig. 1). The student instructor then delivers a 30 -min presentation describing botanical characteristics and ethnobotanical information pertaining to the family. The majority of student instructors use PowerPoint (Microsoft, Redmond, Wash.) slides as a teaching aid; however, some have incorporated movie and television clips and the Internet. Student instructors also prepare a one- to two-page handout corresponding to the presentation which is posted on the course website for the students to print and bring to the laboratory session.

A 10-min recess for the students follows the oral presentation. During the recess, the student instructor and teaching assistants assemble five stations, each with an applied exercise that focuses on morphological characteristics, systematic classification, or ethnobotanical information pertaining to the family. To increase student exposure to course concepts and effectively use the $55 \mathrm{~min}$ allotted for completing the exercises, two duplicates of each station are assembled. Students are randomly assigned to cooperative groups of two or three students and provided an assignment worksheet to be completed during the laboratory (Fig. 2). As the students complete the laboratory exercises, the role of the student instructor shifts from a teacher to a coach or facilitator, as has been observed by others using cooperative teaching activities (Bull and Clausen, 2000). In this role, student instructors develop listening and communication skills as they are called upon to clarify concepts and to provide feedback on observations. 


\section{Laboratory Model}

12:20 Organizational details/return papers/introduce student instructor to the class

12:25 Today's laboratory - oral presentation by student instructor

\section{1:05 Recess}

1:15 Student exercises - completed in cooperative groups of two or three

2:10 Distribute take-home assignment/announcements/close

2:15 Dismissal

Fig. 1. Model used for each laboratory session of the plant systematics course.

Rosaceae Laboratory Exercises

Station \#1.

Compare and contrast the sample seeds according to size, shape, color, texture, etc.

From what type of fruit does each one come?

Station $\# 2$.

From the example given, write the floral formula and draw the floral diagram.

Station \#3.

Draw and label the three layers of the pericarp. From what floral part does the pericarp originate?

Which of the three layers are edible?

Station \#4.

Match each fruit with its genus.

A

B

D.

E.

1. Fragaria

.

2. Malus

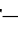

3. Prunus

.

4. Pyrus

F.

Station \#5.

Name the contents of the salad by common name, subfamily and fruit type.

Which does not belong to the Rosaceae family?

Bonus: Name a characteristic used to identify members of the Roseaceae family. It is present in the Maloideae, Rosoideae, and Prunoideae subfamilies, but not in Spiroideae.

Fig. 2. Sample laboratory assignment worksheet developed by undergraduate student instructors for the plant systematics course.

At the end of each laboratory session, students are given a homework assignment to be completed by the following week. Student instructors have been innovative in their choice of assignments and have used plant walks, comics, and crossword puzzles to reinforce laboratory topics. Assignments (laboratory worksheet and homework) are graded by the student instructor and reviewed by the course instructor.

Undergraduate student instructors were asked to participate in a survey after they had taught a laboratory session in 2003-2005. Twentyone undergraduate students taught a laboratory session for academic credit in that time period. Eleven of the 21 student instructors completed the survey (52\% response rate). Six students taught more than one laboratory session either within a single semester or over 2 or 3 years, and the majority of student instructors were female $(63 \%)$.

Additionally, surveys were administered to students enrolled in the plant systematics course in 2003-2005, to determine their assessment of the laboratory sessions. Forty-seven students completed the survey ( $81 \%$ response rate). Means and standard deviations were determined for survey data using SAS (version 9.1.3; SAS Institute, Cary, N.C.). Standard errors were determined using Bonferoni's $t$ statistic $\left(t_{0.05,6,46}\right)$. The Office of Research Protection at the Pennsylvania State University approved both surveys.

STUDENT INSTRUCTORS' SURVEY. Student instructors were asked why they chose to teach a laboratory session (Table 1). None of the students responded that earning an academic credit prompted their decision to teach. This suggests that the students perceived teaching as having value beyond earning an academic credit or grade. Students can be highly motivated to participate in tasks having intrinsic value beyond earning grades (Caprio, 1993). Additionally, student instructors paid tuition for the academic credit earned as a result of teaching a laboratory session, further indicating that they highly regarded this experience. The primary reasons selected for influencing their decision were that teaching was a skill that could be included in their résumés and that plant systematics was an enjoyable discipline.

All of the student instructor respondents "strongly agreed" or "agreed" that preparing and presenting a laboratory session furthered their technical knowledge of the plant family they taught. Ten of the 11 student instructors "strongly agreed" 
Table 1. Responses from undergraduate student instructors $(n=11)$ on their decision to teach a laboratory session for the plant systematics course based on a survey administered in 2003-2005.

\begin{tabular}{|c|c|}
\hline Decision to teach & $\begin{array}{c}\text { Responses } \\
(\text { no. })^{\mathrm{z}}\end{array}$ \\
\hline \multicolumn{2}{|l|}{ Needed a 200- or } \\
\hline 400-level credit & 0 \\
\hline Skill to add to resume & 7 \\
\hline Enjoy plant systematics & 7 \\
\hline $\begin{array}{l}\text { Improve public } \\
\text { speaking skills }\end{array}$ & 5 \\
\hline Other $^{y}$ & 5 \\
\hline
\end{tabular}

or "agreed" that preparing and presenting a laboratory session gave them a greater understanding of the effort involved in teaching and was an enjoyable experience (in each case, the 1lth student "neither agreed nor disagreed" with these survey statements). Also, because the students enjoyed the teaching experience, word-of-mouth may be a factor in the success of recruiting students to teach.

Students' Survey. Students enrolled in the plant systematics course were asked to rate each element of the laboratory sessions (presentations, handouts, laboratory exercises, and homework assignments) for potential to increase their understanding of a plant family (Table 2). The majority of students "strongly agreed" or "agreed" that each element increased their understanding of the topics presented in the laboratory session. All elements were rated statistically similar; however, homework assignments were the lowest ranked element. Student comments criticizing homework assignments included: "the homework assignments didn't have any continuity" and "some homework for labs didn't help at all and were confusing." Student instructors had freedom in developing homework assignments, which resulted in a wide variety of formats which may have been a drawback. Another explanation for the low ranking of homework assignments may have been student disfavor for homework.

Students were also asked their overall assessment of the laboratory
Table 2. Mean assessment ${ }^{\mathrm{z}}$ of students enrolled in the plant systematics course from 2003 to 2005 to teaching elements used during laboratory sessions and developed by undergraduate instructors $(n=47)$.

\begin{tabular}{lccc}
\hline $\begin{array}{c}\text { Teaching } \\
\text { element }\end{array}$ & $\begin{array}{c}\text { Mean } \\
\text { assessment } \\
(\mathbf{1 - 5} \text { scale })^{\mathbf{y}}\end{array}$ & SD & SE $^{\mathbf{x}}$ \\
\hline $\begin{array}{l}\text { PowerPoint } \\
\quad \text { presentation }\end{array}$ & 4.13 & 0.68 & 1.88 \\
$\begin{array}{l}\text { Handout } \\
\text { Laboratory }\end{array}$ & 4.38 & 0.53 & 1.46 \\
$\quad$ exercises & 4.19 & 0.58 & 1.60 \\
Homework & 3.64 & 0.97 & 2.68 \\
\hline
\end{tabular}

${ }^{\mathrm{z} A s s e s s m e n t}$ was determined based on student responses to survey statements: "the PowerPoint presentations for the laboratory sessions increased my understanding of the topics," "the handout for each laboratory session enforced the information in the PowerPoint presentation," "the laboratory exercises enforced the information in the PowerPoint presentation," and "the homework for the laboratory sessions was useful in increasing my understanding of the topic" (PowerPoint; Microsoft, Redmond, Wash.).

${ }^{y}$ Based on student responses to the statements above and using a scale of 1 to 5 , where $1=$ strongly disagree and $\mathbf{5}=$ strongly agree.

${ }^{\mathrm{x}}$ Standard error $(\mathrm{SE})$ was determined using Bonferoni's $t$ statistic; $t_{0.05,6,46}$.

sessions. The majority of students (94\%) "liked" or "strongly liked" the laboratory sessions overall. This response along with the ratings of the individual elements of the laboratory sessions indicated that the students enrolled in the course considered the undergraduate student instructors to be effective teachers.

Reflections as the course INSTRUCTOR. Teaching assistants and departmental funding were critical to the success of this teaching method. Two teaching assistants worked a combined $30 \mathrm{~h}$ per week to help the undergraduate student instructors and assist with other aspects of the course. Their duties pertaining to the laboratory sessions included coordinating with the undergraduate student instructors and the course instructor, purchasing and collecting materials for the laboratory exercises, photocopying, and assembling and disassembling each laboratory session. Further, a greenhouse technician grew a myriad of plant materials used during the laboratory sessions. In addition to supporting the teaching assistants for the course, departmental funds were used to purchase supplies including plant materials, food items, and photocopies.
This teaching method also required extensive planning and organization compared with more traditional laboratory sessions used in another course taught by the instructor. However, this responsibility was shared. Undergraduate student instructors were required to attend two planning meetings, also attended by the teaching assistants, greenhouse technician, and course instructor. During the meetings, materials developed by the student instructors were discussed by the group and modified as needed. Supplies needed for the laboratory session were also determined. Additionally, the student instructor, teaching assistants, and course instructor frequently corresponded via e-mail to finalize details of the laboratory session.

While in college, students should develop skills necessary for success in future careers in addition to gaining technical knowledge. This teaching method can have positive implications for leadership roles entrusted to the student instructors. Various skills are important in a leader (Moore and Rudd, 2005; Wadsworth, 2003), and many of those skills can be developed through experience (Moore and Rudd, 2005; Murphrey and Boyd, 2003; Wadsworth, 2003). This teaching method provided a platform for the student instructors to develop such skills, including assuming responsibility, completing tasks, listening effectively, thinking critically (Wadsworth, 2003), researching technical knowledge, and communicating effectively (Moore and Rudd, 2005). Student instructors assumed responsibility for the completion of the laboratory. Listening skills were developed during planning sessions through input from the course instructor and teaching assistants and during the laboratory session through student questions and comments. Critical thinking was practiced when selecting and developing teaching materials. Technical knowledge of the plant family taught was researched before teaching. Communication skills were developed through discussions during planning meetings, e-mail correspondence to finalize details of the laboratory session, the oral presentation during the laboratory session, and written handouts developed for the laboratory session. 
Students enrolled in the plant systematics course rated the studenttaught laboratory sessions favorably and learned from the teaching materials developed by the student instructors. Students enrolled in the course gained knowledge about plant families and were exposed to different teaching styles and methods. Benefits to the student instructors, as determined through the survey, included increased knowledge of plant families, new perspectives on teaching methodologies, and acquiring a positive item to add to résumés. Additionally, student instructors practiced leadership skills. This teaching method could be integrated into other agriculture courses as well as into those teaching leadership skills.

\section{Literature cited}

Bull, N.H. and J.C. Clausen. 2000. Structured group learning in undergraduate and graduate courses. J. Natural Resources Life Sci. Educ. 29:46-50.
Caprio, M.W. 1993. Cooperative learning-the jewel among motivationalteaching techniques. J. College Sci. Teachers. 22:279-281.

Cox, C.E. 1993. The use of independent study courses to teach lifelong learning skills. North Amer. Colleges Teachers Agr. J. 37:33-36.

Duch, B.J. 1996. Problem-based learning in physics: the power of students teaching students. J. College Sci. Teachers. 25: 326-329.

Henneberry, S.R. and M. Beshear. 1995. Bridging the gap between theory and reality: a comparison of various teaching methods. North Amer. Colleges Teachers Agr. J. 39:15-17.

Fehlis, C.P. 2005. A call for visionary leadership. J. Ext.43(1). 6 Oct. 2006 <http://www.joe.org/joe/2005february/ comml.shtml>.

Moore, L.L. and R.D. Rudd. 2005. Extension leaders' self-evaluation of leadership skill areas. J. Agr. Educ. 46:68-78.

Murano, P.S. and T.D. Knight. 1999a. Determination of learning styles in an introductory food science course. North Amer. Colleges Teachers Agr. J. 43:5053.

Murano, P.S. and T.D. Knight. 1999b. Introducing a cooperative learning term project into an introductory food science course. North Amer. Colleges Teachers Agr. J. 43:21-25.

Murphrey, T.P. and B. Boyd. 2003. Student reaction to a multimedia activity to teach leadership. North Amer. Colleges Teachers Agr. J. 47:38-43.

U.S. Department of Labor. 2006. Occupational outlook handbook: agricultural and food scientists. 21 Sept. 2006 <http://www.bls.gov/oco/home.htm>.

Wadsworth, J. 2003. Seeking the best director leadership: what does it take? Rural Cooperatives 70:25-33.

Walters, D.R. and D.J. Keil. 1996. Vascular plant taxonomy, 4th ed. Kendall/ Hunt Publishing, Dubuque, Iowa. 